\title{
ПРОГНОЗИРОВАНИЕ СПРОСА НА КОНТЕЙНЕРНЫЕ ПЕРЕВОЗКИ ПО ЖЕЛЕЗНОДОРОЖНЫМ ТРАНЗИТНЫМ КОРИДОРАМ ШЕЛКОВОГО ПУТИ
}

\author{
(c) 2021 Оганисян В.А. \\ доцент Департамента менеджмента и инноваций \\ Факультета «Высшая школа управления» \\ Финансовый университет при Правительстве Российской Федерации, Россия, Москва \\ E-mail: vaoganisyan@fa.ru \\ (c) 2021 Налбандян Г.Г. \\ старший преподаватель Департамента менеджмента и инноваций \\ Факультета «Высшая школа управления» \\ Финансовый университет при Правительстве Российской Федерации, Россия, Москва \\ E-mail: ggnalbandyan@fa.ru \\ (c) 2021 Ховалова Т. В. \\ старший преподаватель Департамента менеджмента и инноваций \\ Факультета «Высшая школа управления» \\ Финансовый университет при Правительстве Российской Федерации, Россия, Москва \\ E-mail: tvkhovalova@fa.ru
}

Прогнозирование спроса на грузовые перевозки остается в центре внимания многих эмпирических исследований на протяжении нескольких десятилетий. Исследования спроса на грузовые перевозки, как правило, приводят к широкому диапазону эластичности цен и объемов производства и, следовательно, затрудняют обобщение результатов различных исследований. В данной статье обобщен международный опыт оценки спроса на грузовые перевозки и полученные знания применены для прогнозирования спроса на контейнерные перевозки по железнодорожным «транзитным коридорам»- КНР, ЕАЭС, ЕС.

Ключевые слова: прогнозирование спроса, грузовые перевозки, оценка эластичности, железнодорожные транзитные коридоры.

Литература о спросе на грузовые перевозки разнообразна, исследования отражают интересы множества заинтересованных сторон - участников рынка грузовых перевозок (грузоотправитель, перевозчик, экспедитор и получатель).

В одном из самых ранних исследований совокупного спроса на железнодорожные грузовые перевозки Рао [1] анализирует спрос на железнодорожные грузовые перевозки в Канаде, используя систему одновременных уравнений. Основная цель исследования состояла в том, чтобы количественно оценить влияние макроэкономической активности и интермодальной конкуренции на спрос на железнодорожные перевозки. Для этого Рао построил модель, содержащую три одновременных стохастических уравнения. Первые два уравнения в системе представляют собой спрос, а третье уравнение-предложение. Зависимыми переменными в уравнениях спроса являются объем (измеряемый в миллионе тонн) перевозимого железнодорожным транспортом товара и средняя длина пути следования (измеряемая в милях на тонну). В отличие от этого, зависимая переменная в оставшемся третьем уравнении предложения состоит из тарифов на железнодорожные перевозки (измеряемых как средняя железнодорожная выручка на тонно-милю). Полученные результаты показали, что как доля экспорта, так и объем товарной продукции являются значимыми детерминантами спроса на железнодорожные перевозки, причем предполагаемая краткосрочная эластичность спроса на железнодорожные перевозки ближе к единице. Аналогичным образом, краткосрочная интермодальная конкуренция со стороны автотранспортной отрасли зависит исключительно от дальности перевозок.

Оум [2] сформулировал производную модель спроса на канадские междугородние грузовые перевозки, основанную на трех видах транспор- 
та, железнодорожном, автомобильном и водном, рассматривая грузовые транспортные услуги в качестве промежуточного вклада в производственный и распределительный секторы экономики. При этом в исследовании рассматривается спрос на грузовые перевозки, позволяя более всесторонне учитывать интермодальную конкуренцию между различными видами транспорта (железнодорожным, автомобильным и водным). Исследование показало, что в краткосрочной перспективе спрос на канадские железнодорожные и автомобильные грузовые перевозки менее чувствителен к тарифам грузоперевозок, в то время как чувствительность со временем возрастает, хотя и остается неэластичной.

Льюис и Видап [3] следовали подходу, аналогичному предыдущему исследованию [2], но в контексте США. В ходе исследования была разработана производная модель транспортного спроса с использованием функции транслоговых транспортных издержек для перевозок автотранспортом двух видов транспорта (железнодорожный и автомобильный). Существенной особенностью этого исследования является то, что оно включает в анализ восемь переменных качества обслуживания и использует годовые данные по одной товарной номенклатуре - по собранным автомобилям. При использовании различных статических и динамических характеристик расчетная эластичность спроса по цене железнодорожного транспорта является более значительной, чем у автомобильного транспорта в абсолютном выражении. В частности, расчетная ценовая эластичность грузовых перевозок составляет от -0,52 до -0,57, а железнодорожных перевозок-от -0,92 до -1,08.

Милкович и соавторы [4] построили модель рынка железнодорожных грузов и барж для оценки факторов, оказывающих существенное влияние на ставки железнодорожных и баржевых перевозок зерна, связанного с экспортом из Среднего Запада Иллинойса в экспортные порты Мексиканского залива. Их модель состоит из системы четырех уравнений, причем первые два уравнения представляют собой спрос и предложение для барж, а вторая пара представляет собой уравнения спроса и предложения для железнодорожных перевозок. Результаты, основанные на уравнениях спроса, показали, что оба вида транспорта являются сильными субститутами, в то же время между транспортными ставками и переменными, связанными с экспортом, не существует существенной взаимосвязи. Аналогично, прямая зависимость между ценой и количеством значима только в уравнении предложения железнодорожных перевозок.

Митчелл [5] проанализировал австралийский спрос на контейнерные перевозки тремя видами транспорта: автомобильным, железнодорожным и воздушным. Для оценки использовались две различные функциональные формы: обобщенная функция транслога затрат и агрегированная линейная логит-система распределения затрат. Результаты, полученные на основе линейной динамической логит-модели, свидетельствуют о том, что в краткосрочной перспективе спрос на контейнерные железнодорожные перевозки в Австралии является относительно неэластичным во всех коридорах, а также остается относительно неэластичным в долгосрочной перспективе для коротких и средних маршрутов. Наконец, спрос на контейнерные морские перевозки является эластичным и более чувствительным к средне-и дальним маршрутам.

Бэбкок и Гейл [6] изучили спрос на железнодорожные перевозки зерна в США для основных сырьевых товаров, таких как пшеница и соя, в течение 1980-2010 годов. Авторы приняли двухрегиональную модель пространственного равновесия, подход, разработанный Юи и Фуллером [7]. Основными переменными в исследовании являются перевозки зерна (измеряемые в тысячах тонн) по железной дороге, цена железнодорожных перевозок (измеряемая как доход от железнодорожных перевозок за тонну), производство зерна (соя, кукуруза, пшеница и сорго), ставки барж (для представления перекростной эластичности спроса на железнодорожные перевозки зерна). Полученные результаты, основанные на обобщенном методе моментов, предполагают, что потребность в железнодорожном зерновом транспорте существенно определяется всеми рассмотренными выше объясняющими переменными. Собственная цена, эластичность выпуска зерна и перекрестная эластичность железнодорожного зернового транспорта составили $-1,23,0,95$ и 0,48 соответственно.

Исследования спроса на грузовые перевозки, как правило, приводят к широкому диапазону эластичности цен и объемов производства и, следовательно, затрудняют обобщение результатов различных исследований. В дополнение к первичным исследованиям некоторые аналитики также рассматривают предыдущие экономе- 
трические исследования спроса на железнодорожные и автомобильные грузовые перевозки для достижения консенсуса относительно возможного диапазона эластичности [8; 9]. В своем обзоре эластичности рынка автомобильных и железнодорожных грузовых перевозок Оум и др. [9] изучили 17 исследований грузовых перевозок из Азиатско-Тихоокеанского региона, Великобритании и Северной Америки и представили результаты по всем основным товарным группам. Согласно их исследованию, эластичность цен по всем сырьевым товарам находится в диапазоне от -0,60 до -1,52. Аналитики также приводят возможные причины получения широкого диапазона эластичности в существующей литературе. Это интенсивность интермодальной конкуренции между различными способами перевозок, различия в географических местоположениях и временных горизонтах, степень агрегации на рынках и использование различных функциональных форм.

В недавних исследованиях для анализа совокупного спроса на грузовые перевозки использовались многомерные эконометрические методы временных рядов, такие как коинтеграция и модели векторной авторегрессии [10; 11]. Раманатан [10] рассматривает долгосрочную связь между эффективностью индийского транспортного сектора с использованием двухэтапной модели коинтеграции Энгла-Грейнджера и коррекции ошибок. Совокупная пассажирская и грузовая транспортная активность трех видов транспорта-автомобильного, железнодорожного и воздушного-суммируется для разработки отдельной эконометрической модели как пассажирского, так и грузового транспорта. Исследование показало, что промышленное производство и индекс цен определяют долгосрочный спрос на грузовые перевозки. Предполагаемая долгосрочная эластичность объема производства и цен на грузовые перевозки составляет 1,183 и -0,188, а их значения в краткосрочной перспективе - 0,994 и 0,072 соответственно.

Вейвира и соавторы [11] также применили векторную авторегрессию для изучения влияния ВВП, тарифа на грузоперевозки и международной торговли на контейнерный спрос на железнодорожные перевозки в Австралии к годовым данным за период 1970-2011 гг. Результаты, полученные с помощью функций импульсного отклика (IRF) и декомпозиций дисперсии ошибок прогноза, показали, что двумя наиболее важными детерминантами спроса на железнодорожные перевозки являются тарифы на грузоперевозки и вариация австралийского доллара. В частности, снижение курса австралийского доллара способствует росту спроса на железнодорожные перевозки в Австралии. Кроме того, авторы также считают, что в долгосрочной перспективе существует отрицательная и значимая связь между тарифами грузоперевозок и спросом на железнодорожные перевозки.

Шен и др. [12] использовали шесть эконометрических моделей для получения эластичности выпуска для автомобильного и железнодорожного грузового транспорта, а также для различных товарных групп. Авторы выявили некоторые вариации в результирующих коэффициентах (эластичности), полученных с помощью различных методов. Предполагаемая долгосрочная эластичность выпуска колеблется от 0,720 до 1,485 . В исследовании также сравнивается эффективность прогнозирования всех моделей с использованием критерия средней абсолютной ошибки прогнозирования (МАРЕ) и делается вывод, что ни одна из моделей не превосходит другие во всех ситуациях.

Андерссон и Элгер [13] исследовали эмпирическую связь между шведским грузовым транспортом (совокупным, а также для каждого конкретного вида транспорта, такого как автомобильный, железнодорожный и морской) и экономической активностью (ВВП, промышленное производство, импорт и экспорт) на трех различных временных горизонтах (краткосрочном, среднесрочном и долгосрочном). Полученные результаты свидетельствуют о том, что временные изменения в экспорте и импорте в основном обусловливают колебания спроса на грузовые перевозки в краткосрочной и среднесрочной перспективе, в то время как спрос на грузовые перевозки слабо связан с ВВП. Однако в долгосрочной перспективе ВВП в сочетании со спросом на грузовые перевозки оказывают значимое положительное влияние на спрос на грузовые перевозки по всем видам транспорта. Долгосрочная эластичность спроса по доходу для автомобильного транспорта составила 0,936, для железнодорожного транспорта - 1,918 и 2,649 для морского транспорта. Из-за отрицательной константы прогнозируемый рост спроса на грузовые перевозки не так высок, как может показать эластичность. Кроме того, поскольку модели спроса включают в себя как ВВП, 
так и константу, прогнозируемый рост спроса на грузовые перевозки может быть как выше, так и ниже роста ВВП. В исследовании делается вывод о том, что спрос на железнодорожные перевозки растет быстрее, чем экономика, когда темпы роста ВВП превышают 1,4 процента, и снижаются, когда темпы роста ВВП составляет менее 0,7 процента.

Прогнозы спроса на железнодорожные перевозки Восток-Запад-Восток

В последние годы было опубликовано несколько прогнозов относительно потенциала контейнерных железнодорожных перевозок между Азией и Европой. Ниже представлены результаты исследований, проведенных С.Д.Гливом [14], Центром интеграционных исследований ЕАБР [15] и UIC [16]. Сравнение результатов прогнозирования показывает возникающие различия, зависящие от временного горизонта и применяемой методологии.

Исследование, проведенное по заказу Комитета по транспорту и туризму европейских парламентов Стиром Дэвисом Гливом, оценивает степень, в которой грузовые перевозки морским или воздушным транспортом могут перейти на железнодорожные в результате развития и улучшения железнодорожных услуг. Было сделано несколько предположений относительно уровня обслуживания, которое различные виды транспорта могли бы предложить между Дальним Востоком и Европой. Кроме того, была изучена стоимость различных товаров, перевозимых в настоящее время между Дальним Востоком и Европой морским и воздушным транспортом, с учетом стоимости более быстрого транзита. Было подсчитано, что если бы стоимость груза, отправляемого морским транспортом, превышала 8500 евро за TEU, то грузоотправителям было бы выгоднее отправлять его по железной дороге с меньшими затратами. Таким образом, из двухпутного морского фрахта в размере 40 миллионов TEU (включая пустые возвратные контейнеры) в 2040 году около 2,5 миллионов TEU можно было бы перевести на железную дорогу по данной цене. Было также отмечено, что если бы груз, отправляемый воздушным транспортом, имел стоимость менее 550 евро за килограмм, то было бы более рентабельно отправлять его по железной дороге. На практике средняя стоимость авиаперевозок через европейские аэропорты в настоящее время составляет примерно 200 евро за килограмм. Это говорит о том, что железная дорога могла бы стать привлекательной альтернативой воздуху, если бы существовала пропускная способность железных дорог между подходящими конечными точками с приемлемым общим временем транзита.

Согласно исследованию, подготовленному Евразийским Банком развития, сохранение транспортных субсидий китайскими провинциями является ключевым фактором дальнейшего роста контейнерных перевозок между Китаем и ЕС через Евразийский экономический союз. Рост железнодорожных контейнерных перевозок между Китаем и ЕС в 2011-2019 годах с 14000 TEU до 374800 TEU был достигнут при ставке железнодорожных перевозок в размере 2400-3000 долларов США за TEU (субсидированная примерно на 40\% стоимости).

Помимо тарифных барьеров в исследовании ЕАБР был выявлен ряд нетарифных барьеров, включая инфраструктурные барьеры, пограничные/таможенные барьеры и административноправовые барьеры. Подчеркивается, что на будущий рост трансъевразийского транзита накладывается критическое инфраструктурное ограничение из-за низкой транспортноперерабатывающей мощности польских железных дорог, в том числе пунктов пропуска на польско-белорусской границе.

Обзор изменений ставок морских контейнерных перевозок, которые используются для перевозок по маршруту Азия-Европа (ШанхайСеверная Европа и Шанхай-Средиземноморье), демонстрирует значительные колебания за период в 2009 г. по 2020 г. С 2009 по 2017 год фрахтовые ставки снизились почти в два раза $\$ 1400$ за TEU до $\$ 770$ за TEU, а в 2020 году вновь выросли до \$ 2318 за TEU. Соответствующие индексы до 2020 г. двигались бессистемно, демонстрируя ежегодные темпы роста / снижения на 30-50\%. Ставки на морские контейнерные перевозки начали расти с августа 2020 года. К 45 неделе прирост стоимости на морские перевозки составил 70\% по сравнению с той же неделей в прошлом году. Не смотря на это в сентябре 2020 года глобальный спрос на контейнерные перевозки вырос на 7\% по сравнению с 2019 годом по данным Container Trade Statistics (CTS)*.

В настоящее время большинство действу-

* Фрахтовый индекс SCFI. [Электронный ресурс]. URL: https://en.sse.net.cn/home (дата обращения 31.12.2020). 
ющих железнодорожных маршрутов, соединяющие Китай со странами ЕС в соответствии с графиком, опубликованным Китайская корпорацией железнодорожных контейнерных перевозок [17], проходят через государства-члены ЕАЭС. В настоящее время не существует единого тарифа на транзитные грузоперевозки. Каждая железнодорожная компания, эксплуатирующая трансконтинентальный маршрут, использует свои собственные тарифы грузоперевозок и их изменения не синхронизированы. Кроме того, одной из важных составляющих тарифа на транзитные грузоперевозки являются расходы на содержание подвижного состава, который может принадлежать грузоотправителю или железнодорожной компании или использоваться в лизинг. Таким образом, ни одна железнодорожная компания не может изменить свои тарифы грузоперевозок, чтобы резко повлиять на совокупную конечную величину стоимости перевозок, не выходя за пределы своего диапазона рентабельности. Возможными путями уменьшения тарифа грузоперевозок являются одновременное снижение тарифов всеми заинтересованными сторонами или предоставление государством преференций в рамках политики стимулирования международных железнодорожных грузовых перевозок, позволяющей национальному перевозчику снижать свои тарифы.

На основе анализа доступных источников информации следует сделать вывод, что китайскими властями в настоящее время используется децентрализованная система по субсидированию железнодорожных контейнерных перевозок. Субсидии предоставляются только администрациями соответствующих провинций и муниципалитетов, подчиненных центральному правительству, и только для трансконтинентальных железнодорожных маршрутов.

Как отмечает Бринза [18], средняя сумма субсидий варьируется от региона к региону и находится в диапазоне \$1750-2000 за TEU, в то время как стандартная ставка фрахта, взимаемая за перевозку контейнера из Китая в Европу, составляет около $\$ 4500$ за TEU; таким образом, субсидия снижает ее до \$2500. Как правило, региональные субсидии варьируются от 750 до 3500 долларов США за TEU. Китай начал сокращать субсидии на грузовые перевозки начиная с 2020 года. Данная тенденция обусловлена растущим спросом на контейнерные перевозки из КНР в ЕС ввиду того, что железнодорожные маршруты позволяют осуществлять перевозки с большей скоростью, частотой и регулярностью, чем морские перевозки. Китайское правительство ожидает, что эти факторы компенсируют неравенство в тарифах на перевозку грузов.

Политика субсидирования в Китае существенно повлияла на экономику международных железнодорожных контейнерных перевозок, что исказило соотношение фактических транспортных расходов и тарифов. Однако фактическое снижение ставки фрахта делает перевозку широкого спектра грузов из Китая в Европу железнодорожными контейнерами коммерчески выгодным предложением, что побуждает грузоотправителей переходить с морских путей на железные дороги. В таблице 1 представлена информация по сравнительной динамике тарифов на железнодорожную перевозку контейнерных грузов.

Согласно результатам моделирования Международного союза железных дорог, в сотрудничестве с Инфраструктурным экономическим центром (IEC) по развитию евразийского коридора [16], железнодорожный транзит более чувствителен к цене, чем к скорости. Увеличение скорости движения по транзитным маршрутам, запуск регулярных линий из Южной Кореи и Японии, а также использование единой накладной МГК/СМГС для международных железнодорожных перевозок положительно сказываются

\section{Таблица 1. Сравнительная динамика тарифов на железнодорожную перевозку контейнерных грузов и объемов перевозок на маршрутах КНР - Европа (оценка эластичности спроса по тарифу) (2011-2019 гг.)}

\begin{tabular}{|l|c|c|c|c|c|c|c|c|c|}
\hline & 2011 & 2012 & 2013 & 2014 & 2015 & 2016 & 2017 & 2018 & 2019 \\
\hline $\begin{array}{l}\text { Контейнерные перевозки КНР - } \\
\text { Европа, тыс. ТЕU }\end{array}$ & 14 & 28 & 30 & 44 & 80 & 148 & 175 & 288 & 374,8 \\
\hline $\begin{array}{l}\text { Средний тариф на железнодо- } \\
\text { рожную перевозку контейнерных } \\
\text { грузов КНР - Европа с учетом } \\
\text { субсидий, \$/ТЕU }\end{array}$ & 4500 & 2375 & 2725 & 2875 & 2875 & 2875 & 2900 & 2925 & 2893 \\
\hline
\end{tabular}

Источник: составлено авторами на основе данных ERAI

ERAI Композитный индекс. [Электронный ресурс]. URL: https://index1520.com/ (дата обращения 20.09.2020). 
на росте объемов перевозок. С другой стороны, сокращение железнодорожных субсидий в Китае и программ развития портов являются факторами, наиболее уменьшающие роста объема перевозок. Пропускная способность пограничных переходов и скорость пограничных операций также имеют важное значение, но их влияние на привлекательность железных дорог как способ грузоперевозок уменьшается. Наиболее выгодным для рынка вариантом развития является сценарий, который сочетает в себе увеличение скорости/сокращение транзитного времени, более широкое использование электронных технологий и снижение общей цены грузоперевозок через коридоры.

При более реалистичном сценарии снижение китайских железнодорожных субсидий с 50\% до $20 \%$ станет критическим стрессовым фактором для устойчивости Евразийской железнодорожной транзитной системы. Это должно привести к перераспределению потоков между различными коридорами и изменению структуры рынка.

Маршруты, проходящие через Казахстан, скорее всего, будут затронуты первыми снижением субсидий. Это объясняется тем, что большая часть перевозимых в настоящее время грузов зависит от субсидий, которые затем будут переведены в море, за исключением товаров, чувствительных ко времени или требующих особых условий транспортировки.

По мнению Международного союза железных дорог наилучшим решением для смягчения этих трудностей является скоординированная совместная работа по коридорам, которая может стать важной частью международной политики устойчивого развития. Целью инициативы является развитие железнодорожных перевозок по евразийским коридорам, от океана до океана, за счет дальнейшей интеграции сегментов 1520 мм и 1435 мм. Это может повысить общую конкурентоспособность железнодорожных перевозок, в том числе при неблагоприятных внешних условиях, и помочь справиться с неравенством потоков в разных направлениях благодаря созданию сбалансированной сети логистических узлов, сочетающих транзитные потоки с экспортом и импортом.

Также стоить отметить, что по данным акционерного общества «Объединенная транспортно-логистическая компания - Евра- зийский железнодорожный альянс» рекордный трафик 2020года с использованием сервисов ОТЛК ЕРА был обусловлен несколькими причинами, в том числе, новыми технологическими решениями, разработанными транспортными департаментами РЖД, КТЖ и БЖД. В частности, был утвержден новый маршрут движения поездов через пограничный пункт Озинки / Семиглавый Мар, при этом пропускная способность транзитного коридора увеличилась на три пары поездов в сутки. Более того, была согласована технология, позволяющая перевозить порожние вагоны составами до 114 условных вагонов.

Кроме того, из-за ограничений, наложенных на авиаперевозки, железнодорожный путь, предлагаемый ОТЛК ЕРА, начал выполнять стратегическую роль надежного связующего звена между Китаем и Европой для бесперебойной доставки почты*.

И наконец третьим фактором, смягчающим эффект от уменьшения субсидий, является начало отгрузки санкционной продукции из Европы в Китай по территории России с использованием технологии электронной печати. В Китае растет спрос на импортные продукты питания, что во многом происходит из-за роста уровня потребления и роста покупательной способности китайского населения, поскольку постепенно формируется китайский средний класс. Европейские грузоотправители также заинтересованы в этих поставках, и железнодорожный транзит открывает для них новые рыночные возможности для доставки своей продукции в максимальной безопасности и в гарантированные сроки.

Полученные результаты свидетельствуют о том, что временные изменения в экспорте и импорте в основном обусловливают колебания спроса на грузовые перевозки в краткосрочной и среднесрочной перспективе, в то время как спрос на грузовые перевозки слабо связан с ВВП. Однако в долгосрочной перспективе ВВП в сочетании со спросом на грузовые перевозки оказывают значимое положительное влияние на спрос на грузовые перевозки по всем видам транспорта.

В тоже время рост Евразийского железнодорожного грузового транзита способствует устойчивому экономическому росту, стимулируя дополнительный рост международной торговли и снижая воздействие на окружающую среду.

* Post Chooses Railways. UTLC ERA. [Электронный ресурc]. URL: https://www.utlc.com/en/news/post-choosesrailways/ (дата обращения 20.09.2020). 
Увеличение скорости движения по транзитным маршрутам, запуск регулярных линий из Южной Кореи и Японии, а также использование единой накладной МГК/СМГС для международных железнодорожных перевозок положительно сказываются на росте объемов перевозок.

Статья подготовлена по результатам исследований, выполненных за счет бюджетных средств по государственному заданию Финуниверситету.

\section{Библиографический список}

1. Rao P. S. Forecasting the demand for railway freight services //Journal of Transport Economics and Policy. - 1978._C. $7-26$.

2. Oum T. H. A cross sectional study of freight transport demand and rail-truck competition in Canada //The Bell Journal of Economics. - 1979.- C. 463-482.

3. Lewis K. A., Widup D.P., Lewis R.A. Deregulation and rail-truck competition: evidence from a translog transport demand model for assembled automobiles //Journal of Transport Economics and Policy.-1982. - C. 139-149.

4. Miljkovic $D$. et al. The barge and rail freight market for export-bound grain movement from midwest to Mexican Gulf: an econometric analysis //Transportation Research Part E: Logistics and Transportation Review. - 2000.- T. 36. - № . 2.- C. 127-137.

5. Mitchell $D$. Australian intercapital freight demand: an econometric analysis //Australasian Transport Research Forum 2010 Proceedings. - 2010.- T. 29.

6. Babcock M. W., Gayle P. G. Specifying and Estimating a Regional Agricultural Railroad Demand Model //Journal of the Transportation Research Forum.-2014.- T. 53.- № . 1.

7. Yu T. H., Fuller S. W. The measurement of grain barge demand on inland waterways: a study of the Mississippi River //Journal of the Transportation Research Forum. - 2005. - T. 44. - № . 1424-2016-117976. - C. 27-39.

8. Clark S., Watling D. Modelling network travel time reliability under stochastic demand//Transportation Research Part B: Methodological.-2005.- T. 39.- № . 2.-C. 119-140.

9. Oum T.H., Waters W. G., Yong J.S. Concepts of price elasticities of transport demand and recent empirical estimates: an interpretative survey //Journal of Transport Economics and policy. - 1992. - C. 139-154.

10. Ramanathan $R$. The long-run behaviour of transport performance in India: a cointegration approach // Transportation Research Part A: Policy and Practice. - 2001.- T. 35. - № . 4.- C. 309-320.

11. Wijeweera A., To H., Charles M. An empirical analysis of Australian freight rail demand //Economic Analysis and Policy.-2014.- T. 44. - № . 1.- C. 21-29.

12. Shen S. et al. Econometric modelling and forecasting of freight transport demand in Great Britain //Proceedings of European Transport Conference.- 2009.

13. Andersson F.N.G., Elger T. Swedish freight demand: short, medium, and long-term elasticities //Journal of Transport Economics and Policy (JTEP). - 2012.- T. 46. - № . 1.- C. 79-97.

14. Steer Davies Gleave, 2018, Research for TRAN Committee: The new Silk Route - opportunities and challenges for EU transport, European Parliament, Policy Department for Structural and Cohesion Policies, Brussels.

15. Центр интеграционных исследований ЕАБР (ЦИИ ЕАБР) (2018) Транспортные коридоры Шелкового пути: потенциал роста грузопотоков через ЕАЭС. Доклад № 49. Санкт-Петербург: ЦИИ ЕАБР. Доступно на: https:// eabr.org/analytics/integration-research/cii-reports/transportnye-koridory-shelkovogo-putipotentsial-rostagruzopotokov-cherez-eaes/ (дата обращения 20.09.2020)

16. UIC FREIGHT DEPARTMENT. Report on Combined Transport in Europe.- 2020. Доступно на: https://uic.org/ IMG/pdf/2020_report_on_combined_transport_in_europe.pdf (дата обращения 20.09.2020)

17. CRCT (2018) CEIBS Column Operations over the Years (2011-2017). Доступно на: http://www.crct.com/index.ph $\mathrm{p} ? \mathrm{~m}=$ content $\& \mathrm{c}=$ index \&a=lists \&catid=22 (дата обращения 20.09.2020)

18. Brinza, A. (2017) China's Continent-Spanning Trains Are Running Half-Empty. Foreign Policy, June 5. Доступно на: http://foreignpolicy.com/2017/06/05/chinas-continent- spanning-trains-are-running-half-empty-one-beltone-road-bri/. (дата обращения 20.09.2020) 